\title{
Malignant Gastrinoma
}

National Cancer Institute

\section{Source}

National Cancer Institute. Malignant Gastrinoma. NCI Thesaurus. Code C65188.

A gastrin-producing neuroendocrine tumor. It is characterized by inappropriate secretion

of gastrin and associated with Zollinger Ellison syndrome. It displays vascular invasion and metastasizes to other anatomic sites. 